\title{
Gene Therapy: A New Approach in Modern Medicine
}

\author{
Azam Yazdani ${ }^{1}$, Zahra Alirezaie ${ }^{1}$, Mohammad Javad Motamedi², Jafar Amani ${ }^{*}$ \\ ${ }^{1}$ Department of Biology, Faculty of Basic Science, Shahed University, Tehran, Iran \\ ${ }^{2}$ Green Gene Company, Tehran, Iran \\ ${ }^{3}$ Applied Microbiology Research Center, Systems Biology and Poisonings Institute, Baqiyatallah University of Medical Sciences, \\ Tehran, Iran
}

Corresponding Author: Jafar Amani, Applied Microbiology Research Center, Systems Biology and Poisonings Institute, Baqiyatallah University of Medical Sciences, Vanak Sq., Molasadra St., Tehran, Iran. Tel: +98-21-82482568, Fax: +98-21-88068924, Email: jafar. amani@gmail.com

Received June 10, 2018; Accepted August 15, 2018; Online Published September 30, 2018

\begin{abstract}
In general, gene therapy is the transfer of a genetic material to treat a disease, or at least to improve the clinical status of a patient. One way gene therapy works is to turn viruses into genetic vectors that carry the gene of interest to the target cells. Based on the genome's nature, these vectors are divided into RNA-based or DNA-based viral vectors. Most RNA-based vectors are derived from simple retroviruses, such as the murine leukemia virus. One major drawback of these viruses is that they are not transferred to non-dividing cells (post-mitotic cells). This problem can be solved by using new retroviral vectors derived from lentiviruses, such as the human immunodeficiency virus (HIV). DNA-based vectors originate from adeno-viruses and adeno-associated viruses (AAVs). An example of gene deletion due to gene therapy is the deletion of the human CCR5 gene in T cells (which control HIV infection). Although available vector systems have the ability to transfer genes to living cells (in the human body), an ideal vector for gene delivery has not yet been found. Therefore, the current viral vectors should be used with great caution in human cases. Moreover, the development of new vectors is necessary.

Keywords: Gene Therapy, Lentivirus Vectors, Viral Vectors, Cancer Therapy

Citation: Yazdani A, Alirezaie Z, Motamedi MJ, Amani J. Gene therapy: a new approach in modern medicine. Int J Med Rev. 2018;5(3):106-117. doi:10.29252/IJMR-050304.
\end{abstract}

\section{Introduction}

Gene therapy has provided treatments for incurable diseases that previously had only temporary remedies. Gene therapy has not been successful for a long time; however, in recent years, effective and long-term cured cases have been reported. Promising results have been achieved for a wide range of genetic diseases including blood disorders, immune deficiency, eye problems, regeneration of nerve cells, metabolic disorders, and various types of cancer. ${ }^{1}$ To date, about 2000 clinical trials have been carried out or are in progress on different patients, and many others are in the process of preparation. On the other hand, the design of gene therapy vectors and their clinical development are progressing rapidly. ${ }^{2}$ In this review, after introducing the gene therapy process, some of the considerable recent achievements of clinical gene therapies are examined by presenting different approaches and introducing general tools, including vectors as the most important gene therapy tool.

Gene therapy has the potential to treat diseases that cannot be treated with conventional medicine. It is applied by transferring one or more nucleic acids into a patient's cells or by modifying a defective gene. The main factors of investment in gene therapy for human diseases include the development of gene therapy vectors, optimization of gene delivery under in vivo and in vitro conditions, and enhancement of the clinical experience. Gene therapy, as an advanced technology, goes beyond the modification of genetic disorders and has spread to a wide range of applications. In fact, promising progress made in the treatment of leukemia using modified chimeric antigen receptors (CAR) of T-cells encouraged Science magazine to select cancer immunotherapy as the most important scientific achievement of 2013. ${ }^{3}$ Effective approaches to clinical gene therapy include gene delivery to non-dividing cells and tissues (post-mitotic cells) in vivo, or gene delivery to autologous cells out of the body (ex vivo) in which the gene is transferred to the patient through adoptive transfer (Figure 1). Among viral vectors, the adeno-associated viruses (AAVs) have shown the highest clinical success in in vivo gene transfer (Figure 2). Owing to the wide range of serotypes and capsids, they can target a variety of cells and tissues. Clinical gene therapy in vitro focuses on gene transfer to autologous hematopoietic stem cells (HSCs) for the treatment of various diseases, especially hematologic ones, and to other blood cells such as different types of $\mathrm{T}$ lymphocytes for immunotherapy.

Copyright $\odot 2018$ The Author(s). This is an open-access article distributed under the terms of the Creative Commons Attribution License (http:// creativecommons.org/licenses/by/4.0), which permits unrestricted use, distribution, and reproduction in any medium, provided the original work is properly cited. 


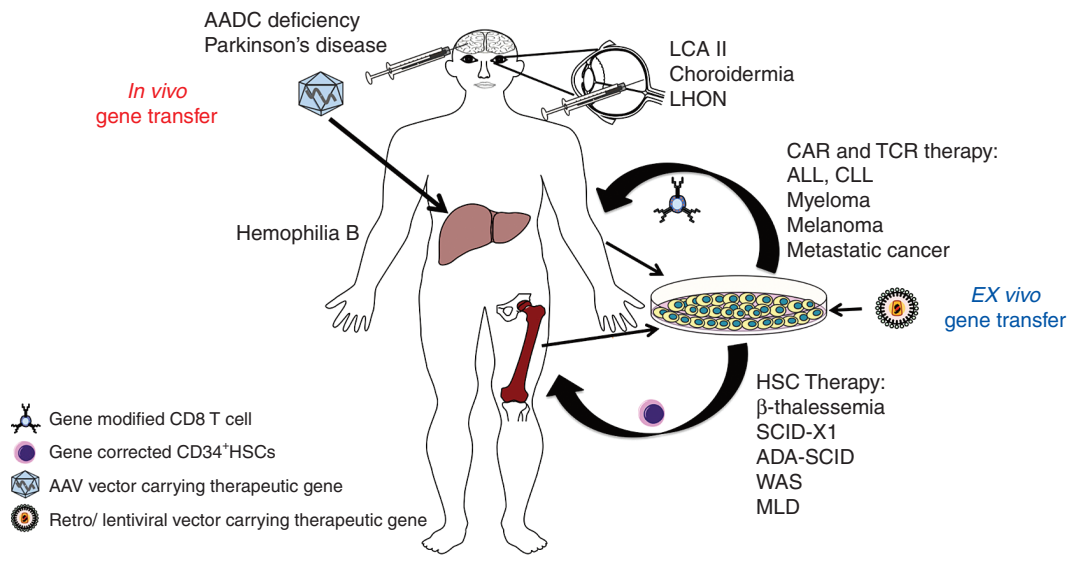

Figure 1. In Vivo Vesus Ex Vivo Gene Therapy for the Treatment of Genetic Diseases and Cancers. In vivo gene therapy involves the direct injection of the vector to convey the intended gene to the patient (into or locally around the target organ). In ex vivo gene therapy, the patient's cells are transferred out of the body, and then the gene is transferred by a vector in a culture medium. Finally, the modified cells are transferred back into the body of the patient. ${ }^{2}$

Retroviral vectors ( $\gamma$-retroviral or lentiviral derivatives) are able to introduce their maximum genetic material into the genome of the target cells and have proven their effectiveness on hematopoietic cells. Early side effects of $\gamma$-retroviral vectors brought about changes in approaches to and the use of lentiviral vectors (Figure 2), which ultimately provided a better, more reliable, and more effective preclinical approach to gene delivery to non-dividing cells. ${ }^{4,5}$

Glybera is the first gene therapy product approved by the European Medicines Agency. It was the first major step in the development of a gene-based medicine. ${ }^{6}$ Recently, significant progress has been made in clinical gene therapy in many single-gene diseases, including early immune deficiency, hemoglobinopathy, hemophilia B, neurological diseases, ocular diseases, and biological treatment of cancer (except oncolytic treatment of cancer). ${ }^{\text {? }}$
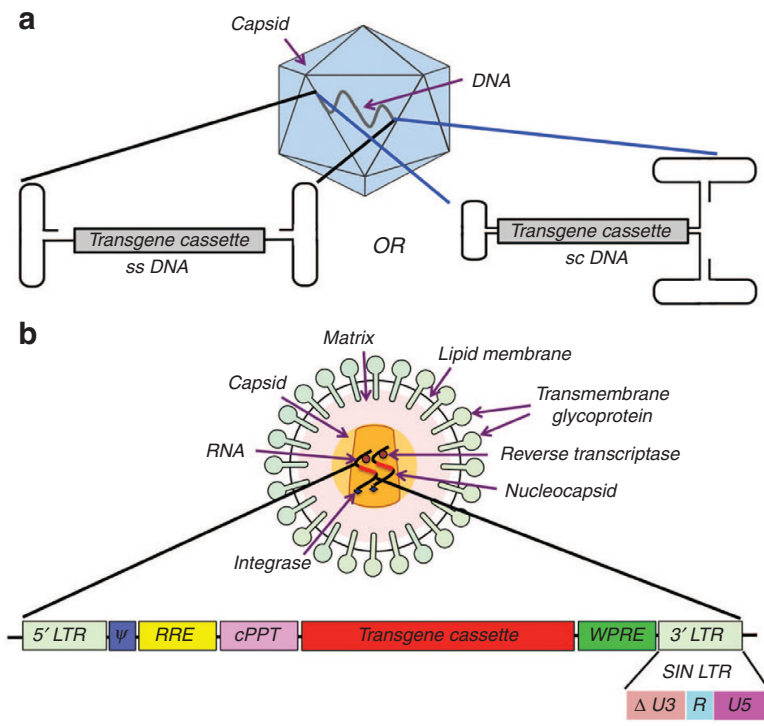

Figure 2. A viral Pattern Widely Used in Clinical Gene Therapy. (a) Adenoassociated virus (AAV) vectors that are widely used for in vivo gene therapy; (b) Lentiviral vectors that can carry a gene up to $8 \mathrm{~kb}$ (kilo base) and are used in many ex vivo gene therapy protocols, especially for transferring the HSC gene. ${ }^{2}$

\section{Approaches to Gene Therapy}

1) Gene modification

Researchers have used the following methods to modify defective genes:

- Replacement treatment: Replacing a natural gene with a non-natural gene through homologous recombination

- Modifier gene therapy: Restoring natural function to a defective gene through selective reverse mutation

- Adjustment of the expression of a specific gene

2) Gene transfer method

There are 3 physical, chemical, and biological methods for gene transfer.

3) Gene transfer to specific cell line

This line is divided into the 2 general categories of somatic gene therapy and sex cell gene therapy.

4) The adoption of the most appropriate genetic engineering (gene injection)

Other forms of genetic engineering include gene targeting and the elimination of specific genes through nuclease engineering, such as zinc finger nucleases, the engineering of I-CreI homing endonucleases, or nucleases produced by TAL effectors. This method is currently being used in human clinical trials. ${ }^{8}$

\section{Vectors in Gene Therapy \\ Retroviruses}

Retroviruses, such as the human immunodeficiency virus (HIV), are a class of viruses that can convert RNA genomes into double-stranded DNA and integrate into host cell chromosomes. One problem with gene therapy using retroviruses is that the integrase enzyme can insert the genome of the virus into any location in the host genome. If the genetic material is inserted into the middle of one of the main genes in the host cell, the function of this gene will be impaired (insertional mutation).

If gene insertion occurs in the cell division process, an uncontrolled cell division (cancer) will occur. This problem has been partially solved by the use of zinc finger nucleases ${ }^{9}$ and specific sequences such as the beta globin control region 
which guide the insertion of the gene into certain positions of the chromosome. ${ }^{1}$

\section{Adenoviruses}

This class of viruses has a double-stranded DNA genome that causes respiratory, intestinal, and ocular infections in humans. When these viruses infect a cell, they insert their DNA molecules into the host's; however, the genetic material of the adenovirus does not integrate into the genetic material of the host cell. Instead, the DNA molecule remains inside the host cell's nucleus, and this foreign DNA is transcribed like any other gene in the cell. The only difference regarding adenoviruses is that when the host cell is divided, the foreign genes are not replicated; as a result, cells generated by cell division will not have additional genes. Therefore, the treatment of a growing cell population with adenoviruses requires the re-injection of them. ${ }^{1}$

\section{Adeno-Associated Viruses}

AAVs comprise a small class of viruses with single-stranded and non-coated DNA. They have the ability to infect both dividing and non-dividing cells with constitutive expression. ${ }^{1}$ The ability of these viruses to be present in cells, in both lysogenic and lytic forms, has made them a good candidate for gene therapy. Another prominent feature of these viruses is their non-pathogenicity for humans in the absence of adenoviruses and herpes viruses as auxiliary viruses. In the absence of auxiliary viruses, these viruses can insert their genetic material into a specific location on chromosome 19.

\section{Herpes Simplex Viruses}

Viruses in this class have double-stranded DNA that infects a specific type of neural cells. Type 1 herpesvirus infection is a common human pathogen that causes cold sores and fever blisters. ${ }^{10}$ Herpes Simplex Virus is a human neurotropic virus which is used for gene transfer mainly in the nervous system. The wild HSV-1 virus can infect neurons and escape the host's immune response; however, this virus may be inactivated and produce a lytic cycle of viral replication. Therefore, a mutant HSV-1 strain that is incapable of replication is typically used. ${ }^{11}$

\section{Non-viral Methods}

Today, non-viral methods are more beneficial than viral ones. Ease of production in a high scale and lower immune responses by the host (host immune system responses) are only 2 of their advantages. In the past, the level of transfection and low expression of the gene were considered as disadvantages of this method. However, recent progress in vector technology has led to the production of molecules and techniques with the same efficiency as the viral techniques. ${ }^{1}$

\section{Ormasil}

The use of Ormasil (silica or modified organic silicate) is another non-viral method. The relative ease of working with silica has made it a good option for gene delivery. The most common method of using silica in gene therapy (due to its low toxicity) is the use of a combination of nanoparticles with amino silicones. However, delivery in the presence of serum, due to the reaction between serum proteins as a limiting factor, reduces the efficiency of this method. ${ }^{12}$

\section{Injection of Naked DNA}

Injection of naked DNA is the simplest non-viral transfer method. Although clinical trials of this method have been successful, gene expression is much lower with it than with other methods. In addition to tests performed with plasmids, experiments have also been performed with naked PCR products. The cellular uptake of naked DNA is generally inefficient. Researchers have, therefore, focused on improving the efficiency of DNA uptake, which has led to the development of new methods, including electroporation, sonoporation, and the use of the "gene gun" where DNA coated with gold particles is introduced into a cell with helium gas at high pressure (Figure 3).

\section{Physical Methods for Improving DNA Transfer Electroporation}

Electroporation is a method that uses high-voltage short pulses to transfer DNA from cell membranes. Small pores caused by electrical shock are formed temporarily on the surface of the membrane, which makes it permeable to nucleic acid. Electroporation can be applied to a variety of cell types; however, high rates of cell death have limited its use in clinical applications. ${ }^{1}$

\section{Gene Gun}

The use of particle bombardment, or gene gun, is another physical method for DNA transfer. In this method, the DNA is coated with gold particles and then placed inside a device which provides the required force to enter the cell. However, if the DNA is located in the wrong place in a genome, e.g., in a tumor suppressor gene, it can induce a tumor. This method has been tested in clinical trials on patients with $\mathrm{X}$-linked severe immunodeficiency (X-SCID), where HSCs were infected with a retrovirus containing the modifying gene, resulting in the successful treatment of $\mathrm{T}$ cell leukemia in 3 out of 20 patients. $^{14}$

\section{Liposome for Drug Delivery}

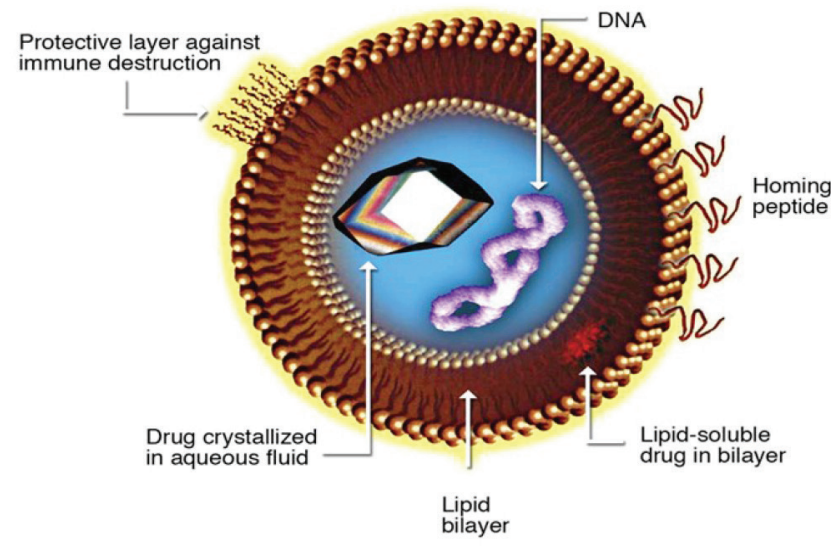

Figure 3. Liposome for Drug Delivery. ${ }^{13}$ 
Sonoporation

Sonoporation uses an ultrasonic frequency to introduce DNA to a cell. This process is considered an ultrasound cavitation in the cell membrane and leads to DNA movement in the cell. ${ }^{1}$

\section{Magnetofection}

With magnetofection, DNA is complexed with magnetic particles, and a magnet is placed under the cellular tissue culture container in order to expose the DNA-containing compound to only one cell layer. This method, which is based on the hypothesis of targeted drug delivery, works by the therapeutic gene linking to the magnetic nanoparticles. The electromagnetic field gradient produced by the ground under the cell culture medium also increases the complex deposition and the rate of transfection. In vivo, the gene-magnetic complex is injected intravenously, and with the help of strong external magnets, it is absorbed and approaches the target. Ultimately, the gene is isolated from the magnetic particles by means of intermolecular restriction enzymes, charge interaction, or degradation of the matrix. This method is often used in laboratory studies to transfer a gene to primary cells and other cells to which it is difficult to transfer genes by other methods. ${ }^{15-17}$

\section{Chemical Methods for Improving DNA Transfer \\ Oligonucleotides}

Synthetic oligonucleotides are used in gene therapy to disable and inactivate genes involved in the disease process. The use of specific antisense for the target gene impairs the transcription of defective genes. Another method is the use of siRNA that leads to the breakdown of a specific sequence of the defective gene mRNA to stop its translation and, thus, its expression.

\section{Lipoplex and Polyplex}

A combination of DNA and polymers is called polyplex. Most polyplexes include cationic polymers which are made based on particle accumulation due to interactions of polyplexes. To improve new DNA delivery to the cell, DNA should be protected from damage and a positive charge. Therefore, anionic and neutral liposomes are used for the formation of lipoplexes as synthetic vectors.

\section{Dendrimers}

The dendrimer is a spherical branched macromolecule. The particle surface can be charged by various methods, and many properties of the final structure of the particle are determined by this surface. In the presence of genetic material such as DNA or RNA, the supplementary charge results in a temporary nucleic acid linkage with the cationic dendrimer. The nucleic acid-dendrimer complex is passed into the cell through the endocytosis. ${ }^{1}$

\section{Hybrid Methods}

Each gene transfer method has its own shortcomings; thus, hybrid methods, which are, in fact, combinations of several techniques, are being developed. A virosome, a combination of a liposome with an inactive HIV or an influenza virus, is an example of a hybrid method. ${ }^{18}$ This hybrid method of gene delivery in respiratory epithelial cells is more efficient than the viral or liposome methods alone. In general, this method involves the mixing of different viral vectors with cationic liposomes or hybrid viruses (Figure 4). ${ }^{1}$

\section{Advantages and Disadvantages of Gene Therapy}

The Advantages of Using Gene Therapy

- Gene Silencing: In the case of an HIV-infected person, gene therapy and gene silencing can protect the patient from pain and suffering before the disease progresses.

- Gene therapy is potentially used to eliminate and prevent hereditary diseases such as cystic fibrosis; it is also a potential way to treat heart disease, AIDS, and cancer. ${ }^{20}$

Disadvantages of Gene Therapy

- The novelty of gene therapy methods is one disadvantage.

- Stimulation of immune response: The gene injected by a virus may cause immune responses due to the presence of the virus inside the body and the pathogenic potential of viral vectors (in one case, the viral vector could improve its ability to cause illness).

- Generation of genetic disorders due to the presence of multigene: The genetic material transferred may not necessarily enter the target cell; even if it does, it may not

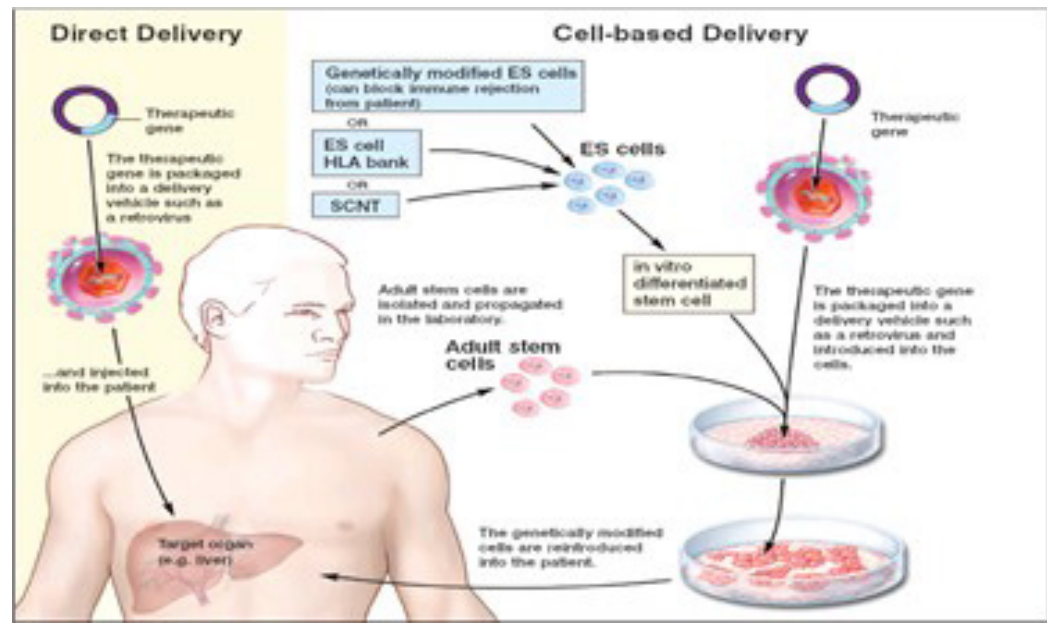

Figure 4. Gene Delivery by Direct and Cell-Based Methods. ${ }^{19}$ 
be placed at an appropriate place in the genome. ${ }^{21}$

\section{Ethical Issues Regarding Gene Therapy}

- Who will decide which attributes are normal and which cause disability or disorder?

- Will gene therapy be available only for the creation of wealth (economic issues)?

- Can spreading gene therapy reduce the social acceptability of individuals who are different?

- Should humans be allowed to use gene therapy to promote essential features such as height, intelligence, or sports abilities?

\section{Applications of Gene Therapy}

Parkinson's Disease

According to independent reports, the effectiveness of gene therapy in Parkinson's disease (PD) has been proven. For example, in one of the proposed methods, the level of a chemical called GABA, the absence of which causes PD, is increased in the brain. In an experiment conducted on 45 volunteers with severe $\mathrm{PD}$, tubes were placed in the areas of the brain associated with movement. Half of the participants were injected with viruses carrying the gene that increases GABA production, and the other half were given an innocuous saline solution (as the control group). After 6 months, those who underwent gene therapy showed a $23 \%$ improvement in movement ability, which was twice the improvement observed for those in the control group.

The study discussed was a randomized controlled trial to investigate the improvement of advanced symptoms of PD using gene therapy. In the research, genes producing the chemical agent glutamic acid carboxylase (GAD) were transferred into the base ganglia cells, which are a set of cerebral areas controlling movement. The transferred GAD gene increased the level of a chemical messenger called GABA. The level of GABA in some parts of the basic ganglia is reduced in people with Parkinson's disease. ${ }^{1}$

In addition to the disease-causing pathways that have so far been discovered, cell-to-cell transfer of the protein mass has been recognized as a mechanism of damage that extends throughout the central nervous system. There is also a growing awareness of the function of the immune system as the main cause of PD in controlling transcription and translation at the onset of the disease. ${ }^{22}$ Increasing our understanding of PD will make it possible to understand the underlying causes of the disease. It is highly critical to cross the blood-brain barrier as a barrier to the introduction of drugs with specific target cells within the brain. ${ }^{23}$ According to a recent study of LRRK2 inhibitor in mammals other than humans, ${ }^{24}$ the long-term use of the inhibitor or genetic manipulation of the target tissue of the Parkinson's drug may have serious consequences. ${ }^{23}$

\section{Alzheimer's Disease}

Mental disorders are among the most common nervous system disorders, and Alzheimer's disease (AD) is the most common cause of dementia worldwide for which there are no effective therapies. AD and a number of frontotemporal dementias (FTDs) are collectively known as tauopathies, which are caused by the abundant accumulation of defective tau in the brain. Recent developments in gene therapy-based approaches, recombinant AAVs (rAAVs) in particular, have provided new tools for the study of $\mathrm{AD}$ and other neurological disorders. ${ }^{25}$

In 2001, a clinical trial of nervous growth factor (NGF) gene therapy was conducted on Alzheimer's disease patients to determine whether decaying neuronal cells in $\mathrm{AD}$, after the onset of the disease, still had the ability to respond to the neural growth factor. In the first attempt, a dysfunctioning nerve gene was transferred to an adult. Based on the results, the decaying neuronal cells of the brain in $\mathrm{AD}$ responded to NGF. All patients showed a nutritional response to NGF; they grew axonal sprouts toward the source of NGF. The brains of 3 patients who underwent one-way gene transfer were examined in terms of the degree of treatability, and it was found that cholinergic neuronal hypertrophy occurred on the side treated with NGF $(P>0.05)$. In the cases of the 2 patients treated with AAV2-mediated and NGF gene transfer, functional markers and cellular signaling were activated. Neurons with Tau damage (proteins that cause microtubule stability) as well as neurons without Tau damage expressed NGF, suggesting that decaying cells can be treated with gene therapy, resulting in the activation of the cellular signaling pathway. No NGF-related side effects were observed. NGFinduced sprouting continued for more than 10 years, longer than the expected assurance period. ${ }^{26}$

According to the Daily Mirror, scientists silenced a gene involved in $\mathrm{AD}$ using the new method of direct drug delivery to the brain. Researchers used small particles called exosomes which are released to the cells and led the drug delivery into the brain of rats. Based on the results of experiments on rats, it has been proven that exosomes have numerous potential applications for carrying specific genes in the brain and can thus be used in gene therapy. One such gene is BACE1. Although this study paved the way for future research and was paid a great amount of attention by the scientific community, it was a preliminary study, and this technology has not yet been tested on human cells for certain reasons that include ethical issues. Many neurological diseases include the degradation and loss of cells. Neurotrophic factors are proteins that increase cell growth in the developmental stage and have a neuroprotective role in a range of neurological diseases; they are ideal candidates for gene therapy in both the central and peripheral nervous systems.

GDNF is a neurotrophic factor in the brain that has attracted considerable attention and is recognized as a neuroprotective agent for the subset of dopaminergic (dopamine-producing) neurons in the midbrain. These neurons decay in patients with PD. GDNF production is a possible therapeutic goal. Several studies have shown that GDNF induction into the brain has been successful in eliminating the behavioral symptoms of PD in animals and preventing the degradation of nigrostriatal dopaminergic pathways. The authors of the study suggested that gene therapy is more effective in that it causes the relatively limited release of GDNF in the cerebral cortex and prevents further degradation of brain structures. Another lentiviral vector has been developed based on 
equine infectious anemia virus (EIAV) and specifically used to infect the brain and spinal cord. Most of the infected cells have a neurological morphology, and VSVG-EIAV-mediated GDNF delivery has been successful in animals with PD.

Research on treating pain areas is mostly focused on the use of HSV vectors that can be used in posterior and peripheral transfers to the posterior root of the ganglia cell. A study on the use of HSV as a GDNF vector reported successful pain relief and low neuro-chemical changes. Although this delivery method has numerous advantages with minimal invasion, the virus can infect the neural cells even through a skin scratch. Prospects for using the HSV system are as follows:

1. Viruses are associated with toxicity and immune responses; nonetheless, using these new methods, viruses can be upgraded, and those parts of the viruses that produce toxicity and immune responses can be eliminated.

2. The replication of the virus in the infected cells has a slight expression in the incubation period.

Several spinal cord inducer viral mediator molecules have been used successfully in a number of methods and models associated with pain. Eaton et al reported the protective effects of an AAV-BDNF neuronal agent. GDNF as an intraspinal cord inducer has not yet been implemented in the peripheral neuropathy model. To date, several studies using the intra-spinal injection of GDNF have been performed by viral expression vector ( $\mathrm{Lv}$ and AAV) in ALS models and ventral root avulsion. ${ }^{1}$

\section{Cystic Fibrosis}

Cystic fibrosis (CF) is a disease which gradually destroys the lungs. Its symptoms include respiratory tract infection, inflammation, deformity, and obstruction. Direct delivery of cystic fibrosis transmembrane regulator (CFTR) gene into respiratory tract epithelium cells as the target tissue has some advantages. However, the physical and immunity barriers in the host's lung create some challenges for the successful transfer of the gene to the respiratory tract. Progress in gene transfer methods, tissue engineering, and animal models have motivated CF research. ${ }^{27}$

\section{History of Cystic Fibrosis Gene Therapy}

Gene therapy for cystic fibrosis began in 1990, just as scientists succeeded in modifying CFTR genes by adding normal gene copies to in vitro cell cultures. In 1993, the first experimental cystic fibrosis treatment was given to a patient in the form of gene therapy. The researchers changed a normal cold virus to act as a vector delivering healthy genes to CFTR cells in the lungs and respiratory tract.

In subsequent studies, other gene delivery methods were tested, such as the use of fat capsules, synthetic vectors, or nose drops, or the drizzling of cells down a flexible tube to CFTR cells lining the airways of the lung. Researchers are now testing an arousal delivery using nebulizers.

Finding the best delivery method for the transfer of natural CFTR genes is just one of the challenges that scientists need to overcome for the effective treatment of cystic fibrosis. Scientists should also:
- $\quad$ Detect the range of affected lung cells;

- Identify the parent cells that produce the CFTR cells;

- Determine how long the treatment should take and how often it should be repeated. ${ }^{1}$

A significant barrier to CF treatment was the lack of an appropriate model for testing gene therapy results. A rat with CF will not suffer a pulmonary problem, while the pulmonary problem is the main cause of disease and mortality in humans. In 2008, CF researchers at the University of Iowa (UI), led by Michael Wales, Director of Pappajohn Biomedical Institute (PBI), with the help of Howard Hughes, a researcher at the Medical Institute, managed to produce a pig model with CF with human-like symptoms. In this study, 2 teams, the first one focusing on the lentivirus and the other on the adenoassociated virus AAV2, introduced CFTR into the airway cells of the pigs with CF. The main advantage of lentiviruses is the direct combination (integration) with the cell genome, which means they are permanent. However, the production of a large amount of lentivirus is challenging, and the virus has not yet been tested in terms of immunity in the human lung.

Another team at the University of California focused on adeno-associated virus AAV2. AAVs are safe for use on humans and are relatively easy to produce in large quantities. The gene delivered by AAV vectors is not permanently integrated into the cell genome but often have long-term gene expression. An important aspect of the AAV study was the molecular upgrade of the virus, so that it was specified for entering the pig's airway cells. Five mutations of the AAV2 virus have been created that are 240 times more effective in infecting pigs' airway cells than the AAV2 itself; these developing vectors can be used as a multi-purpose gene transfer tool in addition to their application in CF gene therapy (Figure 5). ${ }^{28}$

\section{Diabetic Neuropathy}

In a study on a common disorder resulting from chronic diabetes, researchers found that gene therapy is promising in the treatment of diabetic polyneuropathy. Researchers in Boston found that intramuscular injection of a vascular endothelial growth factor (VEGF) gene may help diabetic neuropathy patients. This study included 39 patients who

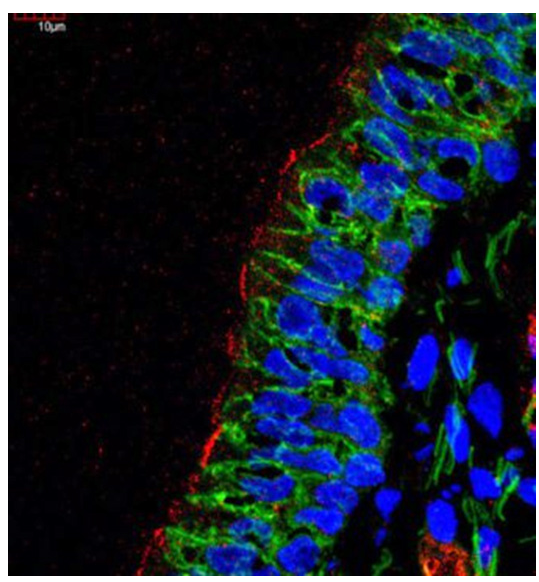

Figure 5. The red color is the CFTR protein transferred by AAV. The blue areas are the nucleus of the airway cells. The green areas are cellular links. ${ }^{28}$ 
received 3 VEGF injections in one leg, plus 11 patients who received placebos. Legs and plantar pain, weakness, and balance problems are signs of diabetic neuropathy. A reduction in the tactile sense means that a foot ulcer may not be detected, and this can result in amputation. Most patients had relatively severe neuropathy and not much hope for recovery. "The VEGF gene used in this study was active and present without any packaging in the virus, which is a great and solid benefit," said Dr. Allan Ropper, Executive Director of the Department of the Neurology at Brigham and Boston Hospitals. The study showed that this form of gene transfer could be relatively safe, but before it can be introduced as a major treatment, further research is needed using a larger study population. ${ }^{1}$

\section{Gene Therapy for Cancer Treatment}

Progress in the genomics of humans over the past 2 decades has shown that cancer is caused by anomalies in the somatic cells of the host genome. These achievements have led many cancer researchers to use treatments based on genetic manipulation and modification to treat cancer and find a potential cure for the disease. Examples include gene therapy using viral (or bacterial) vectors or non-viral vectors, stimulating the immune system (immunomodulation) against tumor cells, manipulation of the tumor cell in order to reduce the tumor tissue, and increasing antigens for better detection of tumors by the immune system of the host. In general, the number of treatments with few side effects has been limited. New generation viral or non-viral vectors significantly decrease risks associated with previous methods of cancer treatment, such as the integration of a retrovirus with a host genome with the risks of mutagenicity or malignancy, immune response against viruses, formation of tumors, drug resistance, or disease relapse.

Several tumor-specific antibodies, genetically-modified immune cells, and vaccines have been developed and are currently available on the market; many others are being tested in clinical trials. Gene therapy is expected to play an important role as part of a multi-faceted treatment for cancer, together with other cancer treatments such as surgery, radiotherapy, and chemotherapy. The type and state of gene therapy are determined based on individual genome components, tumor characteristics, genetics, and host immune status in order to design a multifaceted treatment that is unique to the needs of each individual. ${ }^{29}$

Viral vectors are the main means of gene transfer in gene therapy for cancer. Particularly, the oncolytic viruses that selectively infect and kill cancer cells provide a more promising prospect. Technology for editing and modifying hereditary mutated genes, the interaction with stem cells for tissue regeneration, and the effective use of powerful immune responses to fight cancer also contribute to gene therapy revivification. ${ }^{30}$

\section{Gene Therapy in Pancreatic Cancer}

Pancreatic cancer (PC) is highly lethal and difficult to treat. Only a few patients with pancreatic cancer qualify for surgery, while conventional chemoradiotherapy has considerable toxicity and little effect. Gene therapy has been widely studied as a new method for the treatment of pancreatic cancer; it is considered a new and promising way of treating PC patients in the future. In all types of pancreatic cancers, the P53 tumor inhibitor gene and the mutated K-RAS gene are 2 important samples that have been precisely studied and have provided promising results in in vitro and animal models. Genetic changes such as K-RAS mutations, especially epigenetic disorders of genes associated with a tumor (e.g., P53), are the main symptoms of pancreatic cancer; however, they have not yet been used in clinical trials. Efficient therapeutic targets for gene therapy include the P53 tumor inhibitor gene, K-RAS oncogene, VEGFR anti-angiogenic genes, HSK-TK suicide gene, cytosine deaminase and cytochrome p450, and multiple cytokine genes. A clinical experiment on cytochrome P450 has shown interesting results when combined with ifosfamide; further experiments are being carried out. As an anti-angiogenesis approach, VEGFR is the best choice. Clinical trials of the peptide vaccine derived from VEGFR-2 and the deoxynucleotides vaccine that targets VEGFR-2 have shown some advantages; however, just like anti-angiogenesis, they are not effective for all patients as a single treatment. Thus, they are considered as a complementary therapy. Low gene transfer efficiency is the most important barrier to the use and generalization of gene therapy. The selection of highly efficient vectors that target only cancerous tissues should be taken into consideration. In general, viral vectors have higher transfer efficiency and long-term gene expression, explaining why more than two-thirds of clinical trials are reported to be carried out by viral vectors.

Recently, oncolytic viruses that selectively infect cancerous cells and reproduce have shown promising prospects in this regard. Oncolytic viruses can spread from infected cancerous cells to adjacent and further tissues. Therefore, intratumoral injection can be beneficial even for the treatment of spreading tumors. Systemic applications of oncolytic viruses have shown to be safe for patients with pancreatic cancer, but direct injection of the virus into the primary ulcer is difficult in patients with pancreatic cancer. ${ }^{30}$

\section{Breast Cancer}

Several methods of gene therapy have been developed for breast cancer, the most common cancer among women. Among them are neutralization of the mutation, molecular chemotherapy, proapoptotic gene therapy, anti-angiogenesis gene therapy, immunopotentiation (enhancement of the immune response by increasing the speed and extent of its development and prolonging its duration), and genetic modulation of resistance-sensitivity.

Clinical trials on breast cancer have begun to evaluate the immunity, toxicity, and efficacy of gene therapy. Hybrid methods of gene therapy with chemotherapy or radiotherapy have provided promising results. New gene therapy approaches and improvements in vector design have all led gene therapy to play an important role in the treatment of breast cancer. Most clinical trials focus on TSG P53. The preferred method 
is intramuscular injection of the p53 adenoviral vector. Despite observations of the high expression of the transgenic adenoviral gene, clinical evidence suggests tumor relapse in a small minority of patients. The results of clinical trials on gene therapy for breast cancer have shown little toxicity to date. However, the rate of low clinical response and highexpression of transgenic genes remain controversial. In this regard, future research needs to focus not only on the new transgenic strategy, but also on the development of new gene transfer vectors to help overcome this inefficiency. Predicted methods for treating breast cancer include a multifaceted approach, hybrid therapy, and reduction in tumor size using a surgery called debulking resections, following auxiliary therapies such as synchronous or sequential gene therapy, chemotherapy, and radiotherapy. ${ }^{31}$

\section{Results}

Rapid changes in gene therapy have created numerous innovative methods for treating patients with cancer. Progress in the genetic modification of cancer and immune cells and the use of viruses and bacteria to control cancer cells have led to multiple clinical trials and product development for cancer treatment. However, up to the publication date of this article, no gene therapy product has been approved by the US Food and Drug Administration (FDA). ${ }^{32}$

\section{Number of Tests Per Year}

The number of tests carried out annually is significantly influenced by reports that indicate risks in this area; for example, in 2003 and 2007, the number of tests decreased, but in 2005, 2006, and 2008, considerably high numbers of clinical trials took place. There has also been a growing trend in the number of annual trials since 2012. In recent years, an inadequate number of articles has been submitted to databases due to timeliness of publication, which has in turn led to a delay in obtaining information on most experiments (Figure 6). ${ }^{33}$

\section{Countries Participating in Gene Therapy Experiments}

Clinical gene therapy experiments have been carried out on all 5 continents, measured only in 38 countries. The distribution of the range of tests has not changed much over the past few years and largely reflects the cost of research and development of the experiments. In 2007, 64.9\% of the experiments were carried out in the United States, 23.2\% in Europe, and 6.5\% in Asia (Figure 7).

A significant number of multinational experiments have been conducted, and this number has increased from 16 cases in 2012 to 130 cases in 2017. This indicates a probable increase in mutual cooperation between research centers due to the need for access to a population of patients in more than one country, especially in cases of rare diseases (Table 1). ${ }^{33}$

\section{Future Works}

In the third millennia, gene therapy is considered an important new approach compared to conventional medicine. Gene therapy facilitates continuous, stable, and regular

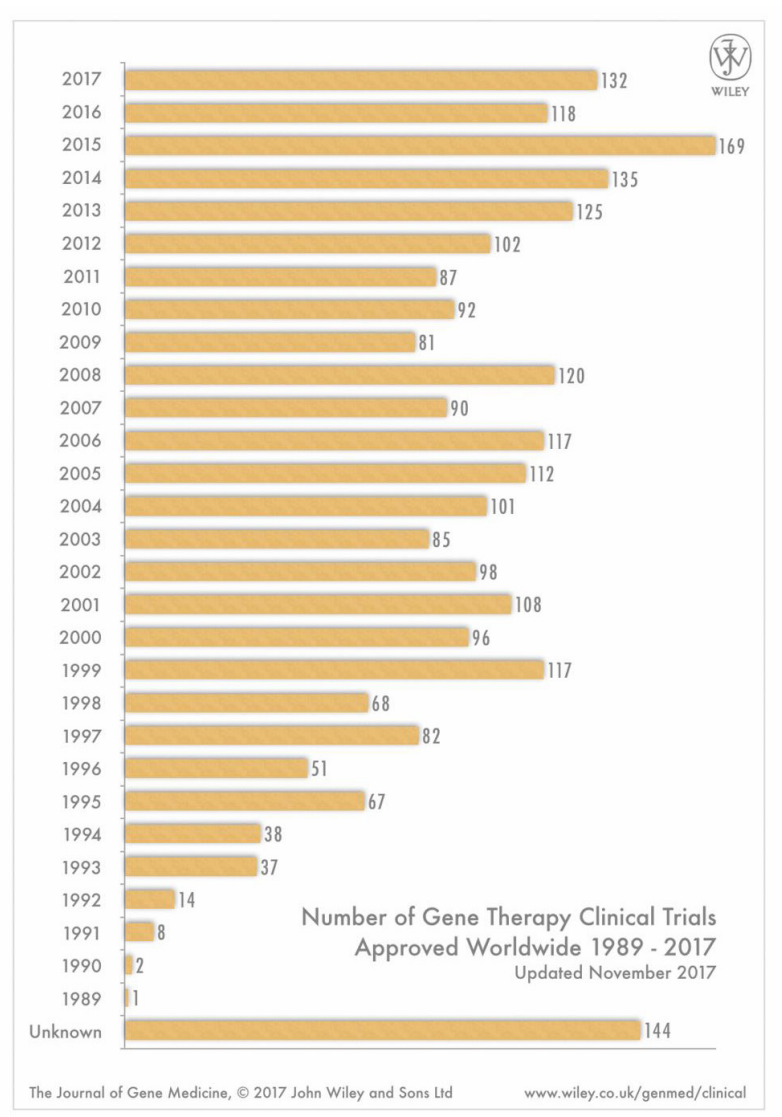

Figure 6. Number of global clinical trials conducted in the period from 1989 to $2017 .^{33}$

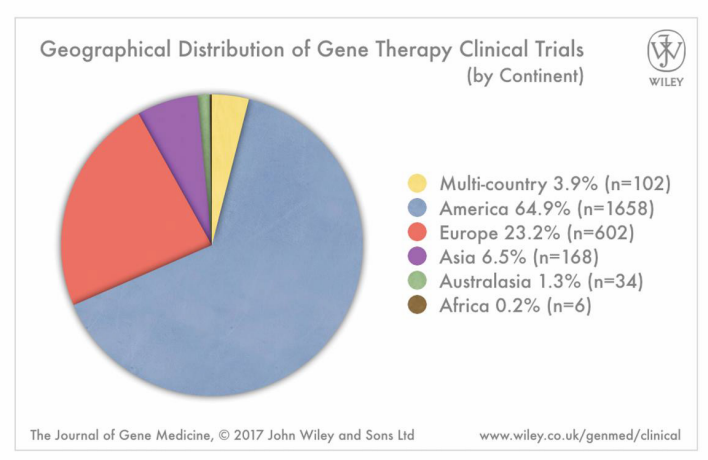

Figure 7. Geographic distribution of gene therapy clinical trials. ${ }^{33}$

expressions of biological agents by the targeted delivery of gene cassettes containing genetic information. When gene therapy is combined with cell therapy, cells become smart vectors for gene therapy purposes. As shown in studies, gene therapy guides powerful biological processes toward disease modification and tissue repair and regeneration. For example, the sustainability, validity, and reinforcement of the performed treatment can be guaranteed by transferring information through genetic mechanisms. Gene therapy utilizes the high potential of stem cell division and transplantation of defensive immune cells that are used to remove the treated cells in specific cases. Other important challenges should be 
Table 1. Important Clinical Experiments in Gene Therapy

\begin{tabular}{|c|c|c|c|c|c|c|}
\hline Disease & Vector and Strategy & $\begin{array}{l}\text { No. of } \\
\text { Patients }^{\mathrm{a}}\end{array}$ & $\begin{array}{l}\text { Follow-up } \\
(\text { mon })\end{array}$ & $\begin{array}{l}\text { Patient Status and Biologic and Clinical } \\
\text { Efficiency }\end{array}$ & Clinic ID & Source \\
\hline $\begin{array}{l}\text { Wiskott-Aldrich } \\
\text { syndrome }\end{array}$ & $\begin{array}{l}\text { Lentiviral vector; in vitro } \\
\text { gene transfer to CD } 34^{+} \text {cells }\end{array}$ & 7 & $10-60$ & $\begin{array}{l}\text { All patients AAW; Stabilized by } \\
\text { transferred cells; clinical advantages and } \\
\text { continuous safety }\end{array}$ & NCT01515462 & 34 and L.N. ${ }^{b}$ \\
\hline $\begin{array}{l}\text { Wiskott-Aldrich } \\
\text { syndrome }\end{array}$ & $\begin{array}{l}\text { Lentiviral vector; In vitro } \\
\text { gene transfer to CD } 34^{+} \text {cells }\end{array}$ & 7 & $9-42$ & $\begin{array}{l}6 \text { patients AAW; } 1 \text { patient died of } \\
\text { infection. Stabilized by transferred cells; } \\
\text { clinical advantages and continuous safety }\end{array}$ & $\begin{array}{l}\text { NCT01347242 } \\
\text { NCT01347346 } \\
\text { NCT02333760 }\end{array}$ & 35 \\
\hline$\beta$-Thalassemia major & $\begin{array}{l}\text { Lentiviral vector; In vitro } \\
\text { gene transfer to CD } 34^{+} \text {cells }\end{array}$ & $3^{c}$ & $24-72$ & $\begin{array}{l}2 \text { patients: continuous injection of the } \\
\text { transferred cells; } 1 \text { patient: independent } \\
\text { injection; } 1 \text { patient: failed injection, then } \\
\text { received rescue cell }\end{array}$ & $\mathrm{N} / \mathrm{A}$ & $\begin{array}{l}36 \text { and } M . \\
\text { Cavazzana } \\
\text { and } \\
\text { BlueBird } \\
\text { Bio }^{b}\end{array}$ \\
\hline$\beta$-Thalassemia major & $\begin{array}{l}\text { Lentiviral vector; In vitro } \\
\text { gene transfer to CD } 34^{+} \text {cells }\end{array}$ & $2^{c}$ & 15 & $\begin{array}{l}\text { Continuous injection of transferred cells; } \\
\text { independent injection. Both patients } \\
\text { healthy }\end{array}$ & NCT02151526 & $\begin{array}{l}\text { M. Cavazzana } \\
\text { and } \\
\text { BlueBird } \\
\text { Bio }^{b}\end{array}$ \\
\hline$\beta$-Thalassemia major & $\begin{array}{l}\text { Lentiviral vector; In vitro } \\
\text { gene transfer to } \mathrm{CD} 34^{+} \text {cells }\end{array}$ & $5^{d}$ & $1-6$ & $\begin{array}{l}\text { Continuous injection of transferred cells; } \\
\text { independent injection. Both patients } \\
\text { healthy }\end{array}$ & NCT01745120 & $\begin{array}{l}\text { BlueBird } \\
\text { Bio }^{b}\end{array}$ \\
\hline Adrenoleukodystrophy & $\begin{array}{l}\text { Lentiviral vector; In vitro } \\
\text { gene transfer to CD } 34^{+} \text {cells }\end{array}$ & 4 & 54-101 & $\begin{array}{l}\text { Continuous injection of transferred cells, } \\
\text { safety in all patients; Stable clinical } \\
\text { advantages in } 3 \text { patients }\end{array}$ & $\mathrm{N} / \mathrm{A}$ & $\begin{array}{l}37,38 \text { and P. } \\
\text { Aubourgb }\end{array}$ \\
\hline $\begin{array}{l}\text { Metachromatic } \\
\text { leukodystrophy }\end{array}$ & $\begin{array}{l}\text { Lentiviral vector; In vitro } \\
\text { gene transfer to CD } 34^{+} \text {cells }\end{array}$ & 20 & $3-60$ & $\begin{array}{l}\text { Continuous injection of transferred cells, } \\
\text { safety in all patients; Stable clinical } \\
\text { advantages in all patients who underwent } \\
\text { treatment before onset of symptoms }\end{array}$ & NCT01560182 & 39 and L.N. ${ }^{b}$ \\
\hline Hemophilia B & $\begin{array}{l}\text { AAV8 vector } \\
\text { Intravenous induction }\end{array}$ & 10 & $16-48$ & $\begin{array}{l}\text { No inhibitor; stable expression of FIX; in } \\
\text { high-dose group, FIX levels of } 5.1 \pm 1.7 \% \\
\text { observed in } 6 \text { treated patients }\end{array}$ & NCT00979238 & 40 \\
\hline Hemophilia B & $\begin{array}{l}\text { AAV8 vector } \\
\text { Intravenous induction }\end{array}$ & 7 & Up to 12 & $\begin{array}{l}\text { No inhibitor; stable expression of FIX in } \\
1 \text { patient }\end{array}$ & NCT01687608 & 41 \\
\hline $\begin{array}{l}\text { B-cell lymphoma or } \\
\text { CLL }\end{array}$ & $\begin{array}{l}\gamma-R V ; \text { in vitro gene transfer } \\
\text { to T-cells; CAR-modified } \\
\text { anti-CD19 cells }\end{array}$ & 15 & $1-23$ & 8 CRs, 4 PRs; ORR 80\% & NCT00924326 & 42 \\
\hline B-cell ALL & $\begin{array}{l}\gamma \text {-RV; in vitro gene transfer } \\
\text { to T-cells; CAR-modified } \\
\text { anti-CD19 cells }\end{array}$ & 5 & $1-4$ & $\begin{array}{l}5 \text { CRs; ORR } 100 \% \text {; } \\
4 \text { patients under allo-HSC transplant; } \\
\text { studied as a general method; } 1 \text { patient } \\
\text { was not qualified for HSC transplant and } \\
\text { returned to initial state. }\end{array}$ & NCT01044069 & 43 \\
\hline B-cell ALL & $\begin{array}{l}\text { Lentiviral vector; in vitro } \\
\text { gene transfer to T-cells; CAR- } \\
\text { modified } \\
\text { anti-CD19 cells }\end{array}$ & 30 & $1-24^{e}$ & $\begin{array}{l}27 \text { CRs; ORR 90\%; 171/5000; } \\
9 \text { patients were recovering; } 3 \text { of them } \\
\text { underwent HSC transplant; } 7 \text { cases of } \\
\text { relapse, } 3 \text { of them occurred after T-cells } \\
\text { loss }\end{array}$ & $\begin{array}{l}\text { NCT01626495 } \\
\text { NCT01029366 }\end{array}$ & 44 \\
\hline B-cell or lymphoma & $\begin{array}{l}\gamma \text {-RV; in vitro gene transfer } \\
\text { to T-cells; CAR-modified } \\
\text { anti-CD19 cells }\end{array}$ & 21 & $\begin{array}{l}\text { Median } \\
= \\
10^{f}\end{array}$ & $\begin{array}{l}4 \text { CRs (at day 28); ORR } 67 \% ; 10 \text { patients } \\
\text { underwent HSC transplant }\end{array}$ & NCT01593696 & 45 \\
\hline PD & $\begin{array}{l}\text { GAD gene by AAV2; in vivo } \\
\text { intrathecal injection }\end{array}$ & & & & $\begin{array}{l}\text { NCT00195143 } \\
\text { NCT00454818 }\end{array}$ & 46,47 \\
\hline LPLD & $\begin{array}{l}\mathrm{LPL} \text { gene by } \mathrm{AAV} 2 \text {; in vivo } \\
\text { intramuscular injection }\end{array}$ & & & & & 48,49 \\
\hline LCA & $\begin{array}{l}\text { RPE } 65 \text { gene by AAV2; in } \\
\text { vivo injection }\end{array}$ & & & Vision improvement & & $50-52$ \\
\hline $\begin{array}{l}\text { Squamous cell } \\
\text { carcinoma of head } \\
\text { and neck }\end{array}$ & $\begin{array}{l}\text { P53 gene by Adenovirus } \\
\text { (Gendicine); in vivo } \\
\text { injection }\end{array}$ & & & & & 53 \\
\hline
\end{tabular}

Abbreviations: AAW: alive and well; ALL: acute lymphocytic leukemia; CLL: chronic lymphocytic leukemia; CR: complete response; N/A: not applicable; ORR: overall response rate; PR: partial response; PD, Parkinson's disease.

${ }^{a}$ As stated in the referenced publications or updated by personal communication.

${ }^{\mathrm{b}}$ Personal communication.

${ }^{c} \beta 0 / \beta E$ genotype.

${ }^{d} 2 \beta 0 / \beta \mathrm{E}, 2 \beta 0 / \beta 0,1 \beta 0 / \beta+$ genotypes.

e Median $=7$.

f 51 days to HSC transplantation media. 
overcome before the effects of this therapeutic approach are fully realized. For example, the efficacy and safety of gene transfer vectors should be improved by formulas and advanced engineering designs which include combining the biological properties of different viruses with synthetic molecules. These enhancements will increase the precision and accuracy of the vector in reaching target tissue and cellular models and reduce cellular constraints in gene transfer and sensors passing through exogenous nucleic acids. Researchers also prevent the activation of inherent and acquired immune systems in gene therapy by upgrading vectors. Ultimately, these changes will ensure the high expression and reproducibility of the transferred gene over a long period of time, and the gene expression will take place in a way similar to the internal pattern (when the gene is replaced).

Progress in the manipulation of genes and their characteristics has led to standardization and comparative evaluation of the performance of vectors in various experiments. The magnitude and specificity of gene modification in its original or natural position, the integration of vectors in genomic safe locations, and the exclusive silencing of alleles by synthetic nucleases and epigenetic modifications provide more opportunities for improving gene therapy strategies. A deeper understanding of the pathology of hereditary, multi-genic, or acquired diseases will lead to the development of new gene therapy strategies. Since gene transfer strategies use live biological agents that can induce long-term effects on patients and their sex cells, long-term care and preventive measures should be considered when using them. Furthermore, due to the limited understanding of stem cell configurations, tissue regeneration, and immune response inspections, there is increasing and undeniable concern about the undesirable effects of genetic manipulation. From a clinical point of view, the clinical delivery of genes and cell therapy requires multidisciplinary specialists and, in some cases, advanced cell processing in the clinical setting. Biological readouts should also be performed to monitor the safety and efficacy of the treatment. Since the first advancements, from registration to marketing, were made in gene therapy, pharmaceutical departments and regulatory agencies have provided quality standards for the production and distribution of these highly specialized medicines. In social terms, the complexity and cost of producing and delivering live biological medicine in conventional healthcare systems challenge the sustainability of these treatments and require the establishment of reimbursable policies so that all patients can benefit from it. Ultimately, whether medical science surrenders to technology laws or takes on more responsibility for these developments is an important ethical issue. Of course, the development of strategies to treat and reduce the suffering of patients justifies our efforts from an ethical point of view. ${ }^{54}$

\section{Conclusions}

Clinical gene therapy has made a number of achievements in the last decade. Several significant successes such as treatments now available for diseases such as cystic fibrosis, diabetes, Alzheimer's disease, Parkinson's disease, various cancers, etc, can be mentioned. In other words, gene therapy can be applied to a wide range of diseases and includes many methods of gene transfer. Initially, LV and AAV vectors were used in experiments, while other vector systems are expected to provide further advancement in their clinical applications. Lessons learned from the successes, problems, and barriers in recent experiments will guide clinical gene therapy practices toward innovation. Next-generation protocols that will help expand the range of diseases treatable by gene therapy are currently being developed. For some of the hardest goals, such as muscular dystrophy and some lysosomal storage and nervous system disorders, there is little chance for immediate success. However, ongoing efforts will lead to the discovery of other treatments in the future. Gene therapy will be a more accurate method of treatment if it is integrated with gene editing tools, as HSC genome editing has recently shown.

\section{Authors' Contributions}

AY and ZA, Collected data and wrote manuscript; MJM; Edited the manuscript, reviewed and approved the final manuscript; JA; supervised the research, reviewed and approved the final manuscript.

\section{Conflict of Interest Disclosures}

The authors declare they have no conflicts of interest.

\section{References}

1. Patil PM, Chaudhari PD, Sahu M, Duragkar NJ. Review article on gene therapy. Int J Genet. 2012;4(1):74-79. doi:10.9735/09752862.4.1.74-79

2. Kumar SR, Markusic DM, Biswas M, High KA, Herzog RW. Clinical development of gene therapy: results and lessons from recent successes. Mol Ther Methods Clin Dev. 2016;3:16034. doi:10.1038/mtm.2016.34.

3. Couzin-Frankel J. Breakthrough of the year 2013. Cancer immunotherapy. Science. 2013;342(6165):1432-1433. doi:10.1126/science.342.6165.1432.

4. Wang $\mathrm{X}$, Shin SC, Chiang AF, et al. Intraosseous delivery of lentiviral vectors targeting factor VIII expression in platelets corrects murine hemophilia A. Mol Ther. 2015;23(4):617-626. doi:10.1038/mt.2015.20.

5. Brown BD. A shot in the bone corrects a genetic disease. Mol Ther. 2015;23(4):614-615.doi:10.1038/mt.2015.38.

6. Yla-Herttuala S. Endgame: glybera finally recommended for approval as the first gene therapy drug in the European union. Mol Ther. 2012;20(10):1831-1832. doi:10.1038/mt.2012.194.

7. Kaufman HL, Kohlhapp FJ, Zloza A. Oncolytic viruses: a new class of immunotherapy drugs. Nat Rev Drug Discov. 2015;14(9):642662. doi:10.1038/nrd4663.

8. Urnov FD, Rebar EJ, Holmes MC, Zhang HS, Gregory PD. Genome editing with engineered zinc finger nucleases. Nat Rev Genet. 2010;11(9):636-646. doi:10.1038/nrg2842.

9. Durai S, Mani M, Kandavelou K, Wu J, Porteus MH, Chandrasegaran S. Zinc finger nucleases: custom-designed molecular scissors for genome engineering of plant and mammalian cells. Nucleic Acids Res. 2005;33(18):5978-5990. doi:10.1093/nar/gki912.

10. Friedmann T, Roblin R. Gene therapy for human genetic disease? Science. 1972;175(4025):949-955. doi:10.1126/ science.175.4025.949.

11. Harwood AJ. Protocols for gene analysis. 1 st ed. Totowa, New Jersey: HumanaPress; 1994.Volume31.doi:10.1385/0896032582.

12. Ramamoorth $M$, Narvekar A. Non viral vectors in gene therapyan overview. J Clin Diagn Res. 2015;9(1):Ge01-06. doi:10.7860/ jcdr/2015/10443.5394. 
13. Alvarez-Erviti L, Seow $Y$, Yin H, Betts C, Lakhal S, Wood MJ. Delivery of siRNA to the mouse brain by systemic injection of targeted exosomes. Nat Biotechnol. 2011;29(4):341-345. doi:10.1038/nbt.1807.

14. Wrobel I, Collins D. Fusion of cationic liposomes with mammalian cells occurs after endocytosis. Biochim Biophys Acta. 1995;1235(2):296-304. doi:10.1016/0005-2736(95)80017-A.

15. Al-Dosari MS, Gao X. Nonviral gene delivery: principle, limitations, and recent progress. AAPS J. 2009;11(4):671-681. doi:10.1208/s12248-009-9143-y.

16. Dobson J. Gene therapy progress and prospects: magnetic nanoparticle-based gene delivery. Gene Ther. 2006;13(4):283287. doi:10.1038/sj.gt.3302720.

17. Jones $\mathrm{CH}$, Chen $\mathrm{CK}$, Ravikrishnan A, Rane S, Pfeifer BA. Overcoming nonviral gene delivery barriers: perspective and future. Mol Pharm. 2013;10(11):4082-4098. doi:10.1021/ $\mathrm{mp} 400467 \mathrm{x}$.

18. Woods NB, Bottero V, Schmidt $M$, von Kalle C, Verma IM. Gene therapy: therapeutic gene causing lymphoma. Nature. 2006;440(7088):1123. doi:10.1038/4401123a.

19. Gao X, Huang L. Potentiation of cationic liposome-mediated gene delivery by polycations. Biochemistry. 1996;35(3):1027-1036. doi:10.1021/bi952436a.

20. Horn PA, Morris JC, NeffT, Kiem HP. Stem cell gene transfer--efficacy and safety in large animal studies. Mol Ther. 2004;10(3):417-431. doi:10.1016/j.ymthe.2004.05.017.

21. Farhood H, Serbina N, Huang L. The role of dioleoyl phosphatidylethanolamine in cationic liposome mediated gene transfer. Biochim Biophys Acta. 1995;1235(2):289-295. doi:10.1016/0005-2736(95)80016-9.

22. Taymans JM, Nkiliza A, Chartier-Harlin MC. Deregulation of protein translation control, a potential game-changing hypothesis for Parkinson's disease pathogenesis. Trends Mol Med. 2015;21(8):466-472. doi:10.1016/j.molmed.2015.05.004.

23. van der Brug MP, Singleton A, Gasser T, Lewis PA. Parkinson's disease: From human genetics to clinical trials. Sci Transl Med. 2015;7(305):205ps220. doi:10.1126/scitranslmed.aaa8280.

24. Fuji RN, Flagella $M$, Baca $M$, et al. Effect of selective LRRK2 kinase inhibition on nonhuman primate lung. Sci Transl Med. 2015;7(273):273ra215. doi:10.1126/scitranslmed.aaa3634.

25. Combs B, Kneynsberg A, Kanaan NM. Gene Therapy Models of Alzheimer's Disease and Other Dementias. Methods Mol Biol. 2016;1382:339-366. doi:10.1007/978-1-4939-3271-9_25.

26. Tuszynski MH, Yang JH, Barba D, et al. Nerve Growth Factor Gene Therapy: Activation of Neuronal Responses in Alzheimer Disease. JAMA Neurol. 2015;72(10):1139-1147. doi:10.1001/ jamaneurol.2015.1807.

27. Oakland M, Sinn PL, McCray PB, Jr. Advances in cell and gene-based therapies for cystic fibrosis lung disease. Mol Ther. 2012;20(6):1108-1115. doi:10.1038/mt.2012.32.

28. Cooney AL, Abou Alaiwa MH, Shah VS, et al. Lentiviralmediated phenotypic correction of cystic fibrosis pigs. JCI Insight. 2016;1(14). doi:10.1172/jci.insight.88730.

29. Amer MH. Gene therapy for cancer: present status and future perspective. Mol Cell Ther. 2014;2:27. doi:10.1186/2052-8426$2-27$.

30. Liu SX, Xia ZS, Zhong YQ. Gene therapy in pancreatic cancer. World J Gastroenterol. 2014;20(37):13343-13368. doi:10.3748/ wjg.v20.i37.13343.

31. Stoff-Khalili MA, Dall P, Curiel DT. Gene therapy for carcinoma of the breast. Cancer Gene Ther. 2006;13(7):633-647. doi:10.1038/ sj.cgt.7700929.

32. Husain SR, Han J, Au P, Shannon K, Puri RK. Gene therapy for cancer: regulatory considerations for approval. Cancer Gene Ther. 2015;22(12):554-563. doi:10.1038/cgt.2015.58.

33. Ginn SL, Amaya AK, Alexander IE, Edelstein M, Abedi MR. Gene therapy clinical trials worldwide to 2017: An update. J Gene Med. 2018;20(5):e3015. doi:10.1002/jgm.3015.
34. Aiuti A, Biasco L, Scaramuzza S, et al. Lentiviral hematopoietic stem cell gene therapy in patients with Wiskott-Aldrich syndrome. Science. 2013;341(6148):1233151. doi:10.1126/ science. 1233151.

35. Hacein-Bey Abina S, Gaspar HB, Blondeau J, et al. Outcomes following gene therapy in patients with severe Wiskott-Aldrich syndrome. JAMA. 2015;313(15):1550-1563. doi:10.1001/ jama.2015.3253.

36. Cavazzana-Calvo M, Payen E, Negre O, et al. Transfusion independence and HMGA2 activation after gene therapy of human beta-thalassaemia. Nature. 2010;467(7313):318-322. doi:10.1038/nature09328.

37. Cartier N, Hacein-Bey-Abina S, Bartholomae CC, et al. Hematopoietic stem cell gene therapy with a lentiviral vector in X-linked adrenoleukodystrophy. Science. 2009;326(5954):818823. doi:10.1126/science.1171242.

38. Cartier N, Hacein-Bey-Abina S, Bartholomae CC, et al. Lentiviral hematopoietic cell gene therapy for X-linked adrenoleukodystrophy. Methods Enzymol. 2012;507:187-198. doi:10.1016/b978-0-12386509-0.00010-7.

39. Biffi A, Montini E, Lorioli L, et al. Lentiviral hematopoietic stem cell gene therapy benefits metachromatic leukodystrophy. Science. 2013;341(6148):1233158. doi:10.1126/science.1233158.

40. Nathwani AC, Reiss UM, Tuddenham EG, et al. Long-term safety and efficacy of factor IX gene therapy in hemophilia B. N Engl J Med. 2014;371(21):1994-2004. doi:10.1056/NEJMoa1407309.

41. Baxalta reports continued progress on phase $1 / 2$ clinical trial of BAX335, investigational gene therapy treatment for hemophilia B. Baxter website. http://www.baxter.com/news-media/newsroom/ press-releases/2015/06_24_15_bax335.page. Published 2015.

42. Kochenderfer JN, Dudley ME, Kassim SH, et al. Chemotherapyrefractory diffuse large B-cell lymphoma and indolent B-cell malignancies can be effectively treated with autologous $\mathrm{T}$ cells expressing an anti-CD19 chimeric antigen receptor. J Clin Oncol. 2015;33(6):540-549. doi:10.1200/jco.2014.56.2025.

43. Brentjens RJ, Davila ML, Riviere I, et al. CD19-targeted T cells rapidly induce molecular remissions in adults with chemotherapyrefractory acute lymphoblastic leukemia. Sci Transl Med. 2013;5(177):177ra138. doi:10.1126/scitranslmed.3005930.

44. Maude SL, Frey N, Shaw PA, et al. Chimeric antigen receptor $\mathrm{T}$ cells for sustained remissions in leukemia. $\mathrm{N}$ Engl J Med. 2014;371(16):1507-1517. doi:10.1056/NEJMoa1407222.

45. Lee DW, Kochenderfer JN, Stetler-Stevenson $M$, et al. T cells expressing CD19 chimeric antigen receptors for acute lymphoblastic leukaemia in children and young adults: a phase 1 dose-escalation trial. Lancet. 2015;385(9967):517-528. doi:10.1016/s0140-6736(14)61403-3.

46. Leone P, Shera D, McPhee SW, et al. Long-term followup after gene therapy for canavan disease. Sci Transl Med. 2012;4(165):165ra163. doi:10.1126/scitranslmed.3003454.

47. Tardieu M, Zerah M, Husson B, et al. Intracerebral administration of adeno-associated viral vector serotype rh.10 carrying human SGSH and SUMF1 CDNAs in children with mucopolysaccharidosis type IIIA disease: results of a phase I/II trial. Hum Gene Ther. 2014;25(6):506-516. doi:10.1089/hum.2013.238.

48. Li B, Ma W, Ling C, et al. Site-Directed Mutagenesis of SurfaceExposed Lysine Residues Leads to Improved Transduction by AAV2, But Not AAV8, Vectors in Murine Hepatocytes In Vivo. Hum Gene Ther Methods. 2015;26(6):211-220. doi:10.1089/hgtb.2015.115.

49. Ferreira $\mathrm{V}$, Twisk J, Kwikkers $\mathrm{K}$, et al. Immune responses to intramuscular administration of alipogene tiparvovec (AAV1$\mathrm{LPL}(\mathrm{S} 447 \mathrm{X})$ ) in a phase II clinical trial of lipoprotein lipase deficiency gene therapy. Hum Gene Ther. 2014;25(3):180-188. doi:10.1089/hum.2013.169.

50. Testa F, Maguire AM, Rossi S, et al. Three-year follow-up after unilateral subretinal delivery of adeno-associated virus in patients with Leber congenital Amaurosis type 2. Ophthalmology. 2013;120(6):1283-1291. doi:10.1016/j.ophtha.2012.11.048. 
51. Simonelli F, Maguire AM, Testa F, et al. Gene therapy for Leber's congenital amaurosis is safe and effective through 1.5 years after vector administration. Mol Ther. 2010;18(3):643-650. doi:10.1038/mt.2009.277.

52. Maguire AM, High KA, Auricchio A, et al. Age-dependent effects of RPE65 gene therapy for Leber's congenital amaurosis: a phase 1 dose-escalation trial. Lancet. 2009;374(9701):1597-1605. doi:10.1016/s0140-6736(09)61836-5.

53. Kaufmann KB, Buning H, Galy A, Schambach A, Grez M. Gene therapy on the move. EMBO Mol Med. 2013;5(11):1642-1661. doi:10.1002/emmm.201202287.

54. Naldini L. Gene therapy returns to centre stage. Nature. 2015;526(7573):351-360. doi:10.1038/nature15818. 